\title{
A Quantitative Study on the Rate of Cell Production in the Bone Marrow of Young Mature Albino Rats.*
}

\author{
By \\ Michihiko Okada \\ Department of Anatomy, Yamaguchi Medical School, Uhe \\ (Director: Prof. Bunsuke Osogoe)
}

The present work is a continuation of the previous studies on the rate of cell production in the thymolymphatic organs $(\mathrm{O} \mathrm{s}$ o g o e et al., 1957; M onden, 1959a; and Ito, 1959), and deals with the rate of mitotic activity in the bone marrow. Its principal objective is to estimate the total number of blood cells newly produced by mitosis per day in the bone marrow of young mature albino rats, and, using the previously reported data on total cellular numbers in the circulating blood and bone marrow of similar rats (M o n de $\mathrm{n}$, $1958 \mathrm{~b}$ and A w a y a et al., 1960), to calculate the time taken for the replacement of a number of cells equal to that in the whole population (turnover time), with respect to each type of blood cells.

It is a very difficult task to make quantitative approaches along this line. So far as the writer is aware, $\mathrm{Kindred}$ is the first who made a series of studies of this type, using rats as material (K in d red, 1938, 1940 and 1942). These studies are chiefly based on cell counts and mitotic counts of given areas in sections of the hematopoietic organs. It should be borne in mind, therefore, that the tedious histologic counting difficulties may cause uncertainty in the results, and that extrapolation of the results from cell counts in limited areas of sections to whole organ can be misleading.

After $\mathrm{K}$ ind red, only fragmentary information has been reported concerning the quantitative aspects of cell production in the bone marrow.

* Aided by a grant to Professor Bunsuke Osogoe from the Ministry of Education (Grant-in-Aid for Fundamental Scientific Research, Cooperative). A preliminary report covering certain phases of this study has been published (O s o g o e and $A$ w a y a, 1.958). 


\section{Material and Methods}

Young mature male albino rats of a subline of the $\mathrm{W}$ ista $\mathrm{r}$ strain weighing around $200 \mathrm{~g}$ were chosen as the standard animals to be examined as in the earlier studies (M o n d e n, 1959a, b; I t o, 1959 and A w a a et al., 1960). They were raised on a standard laboratory diet, which consisted chiefly of unpolished rice, pressed barley and dried small sardine with a small amount of cod liver oil and minerals, supplemented once a week with green vegitables.

They were divided into 5 groups consisting of 5 or 4 animals each. The animals of the first group were killed at 10:00 a.m. and served as controls. Each animal of the other four groups received a single intracutaneous injection of $0.10 \mathrm{mg}$ of colchicine per $100 \mathrm{~g}$ of body weight at 10:00 a.m. Thereafter, the animals were killed at successive intervals from 2 to 8 hours as shown in Table 1 . All rats had been starved since the previous evening. Unlike in the previous experiments by Ito (1959b), adrenalectomy was not performed in the present research.

Table 1. Summary of animal number and body weight of the rats used.

\begin{tabular}{|c|c|c|c|c|c|}
\hline $\begin{array}{l}\text { Time in hours } \\
\text { after colchicine } \\
\text { in jection }\end{array}$ & 0 & 2 & 4 & 6 & 8 \\
\hline \multirow{5}{*}{$\begin{array}{l}\text { Animal No. } \\
\text { and } \\
\text { body weight } \\
\text { in grams }\end{array}$} & $\mathrm{N} 1,200$ & Col. 3,189 & Col. 4, 191.5 & Col. $5,191,5$ & Col. 9,196 \\
\hline & $\mathrm{N} 2,196$ & Col. 6,189 & Col. 7,191 & Col. 8,189 & Col. 12,195 \\
\hline & N 3, 200 & Col. 10,193 & Col. $13,195.5$ & Col. 11, 191 & Col. 20, 196 \\
\hline & N 4,207 & Col. 15, 194 & Col. 14, 195. 4 & Col. 18, 192 & Col. 21, 199 \\
\hline & N 5, 200 & Col. 16, 192 & Col. 17, 191 & Col. 19,198 & - \\
\hline Mean \pm S. E. & $200.6 \pm 1.8$ & $191.4 \pm 1.0$ & $192.9 \pm 1.1$ & $192.3 \pm 1.5$ & $196.5 \pm 0.9$ \\
\hline
\end{tabular}

S. E. : standard error.

Immediately after the animals had been killed by cervical dislocation and bleeding, the tissues to be examined were quickly taken out. For preparing imprint and smear preparations, bone marrow from the distal part of diaphysis of the right femur was used. After that, the marrow was fixed in $\mathrm{Z}$ e n ker-formol to prepare in serial sections.

Differential bone marrow counts and mitotic counts were performed in stamp preparations stained with $\mathrm{May}-\mathrm{Giems}$ a or Giemsa. For differential cell counting, the imprint preparations 


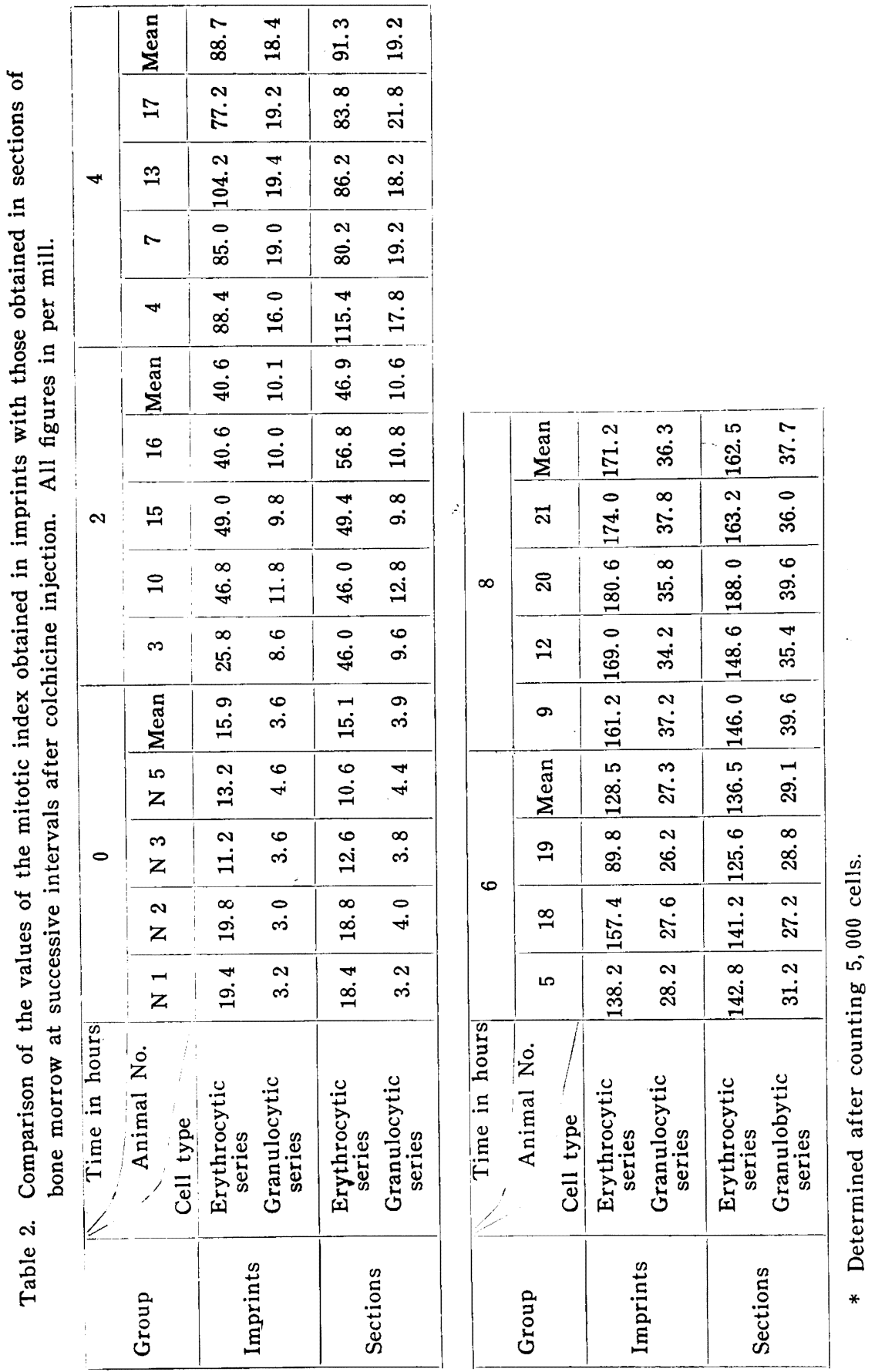


were considered to be preferable to the smear preparations, since cell counting in the former generally gave higher values with respect to the percentage of the nucleated red cells than that in the latter, as will be described in detail elsewhere.

The relative percentage of different types of cells and the mitotic indices were determined after counting 5,000 nucleated cells. In every instance, the figures of the mitotic index obtained in imprint preparations were compared with those obtained in sections. The results are summarized in Table 2 and depicted in Figures 1 and 2. It was found that the results from both imprints and sections well coincided with each other.

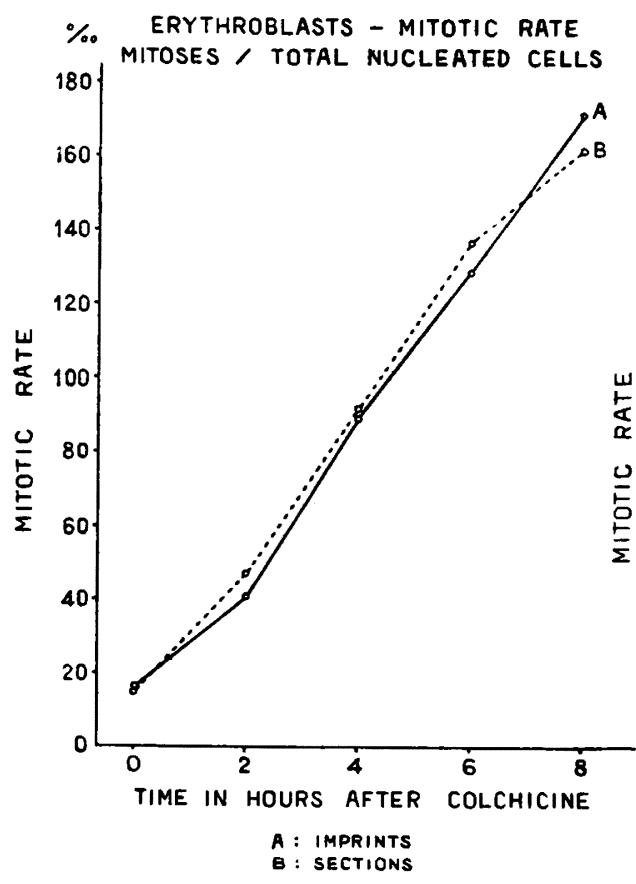

Fig. 1. Comparison of the values of the mitotic index for the nucleated red cells obtained in imprints with those obtained in sections, at successive intervals after colchicine injection.

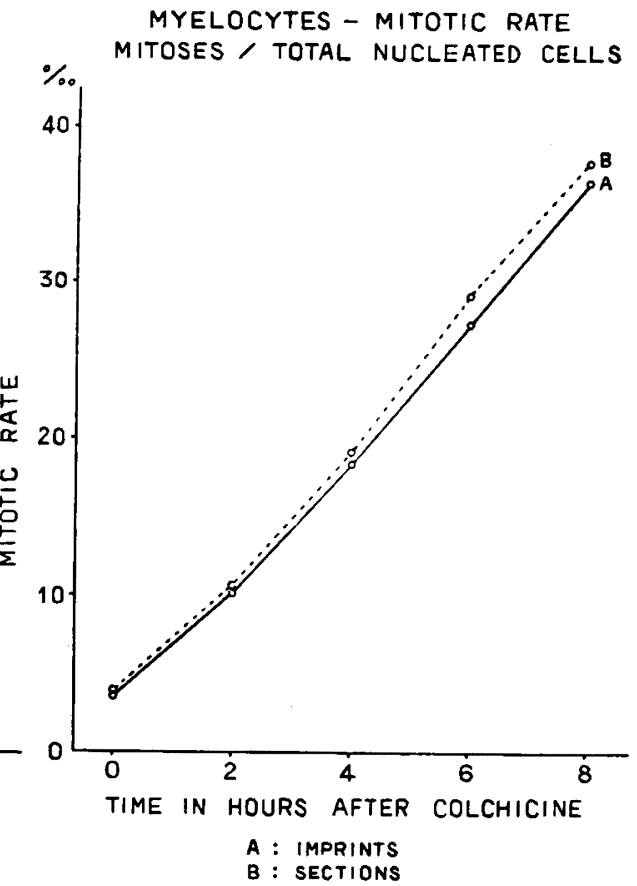

Fig. 2. Comparison of the values of the mitotic index for the myelocytes obtained in imprints with those obtained in sections, at successive intervals after colchicine injection.

Generally, the identification of cell type is difficult because dividing cells lose not only nuclear characteristics but also some cytoplasmic features. Therefore, special attention was directed to 
the identification of dividing marrow cells.

The cells of the erythrocytic series in mitosis may easily be discriminated by their characteristic deep blue cytoplasm tinged with reddish tone and by the chromosomes which are broader and shorter than those of myeloid cells. The identification of the cells of the granulocytic series in mitosis is more easily done because of the presence of the special granules except for myeloblasts. According to the amount of the granules and the basophilic area of cytoplasm, myelocytes were classified into immature, half-mature and mature forms. While the amount of granules increases in this order, the basophilic area of cytoplasm decreases in the same order, and it disappears completely in the mature forms. Myeloblasts are generally smaller in size than myelocytes and have bluish nongranular cytoplasm. Promyeloblasts are slightly larger than myeloblasts and characterize by the presence of a few azurophil granules.

No attempt has been made to present all quantitative data in terms of the amount per $100 \mathrm{~g}$ of body weight. The variances accompanying the averages are the standard errors of the means. For multiplication of the two averages, the resultant variance was calculated by a conventional formula $\pm(\mathrm{Ba}+\mathrm{Ab})$ instead of using the thoretical formula $\pm \sqrt{\mathrm{B}^{2} \mathrm{a}^{2}+\mathrm{A}^{2} \mathrm{~b}^{2}}$, in which $\mathrm{A}$ and $\mathrm{B}$ are respectively the averages, and $a$ and $b$ their respective standard errors. Although the former formula gave generally greater values than the latter, this does not seriously affect the results, provided the variances are sufficiently small in contrast to the averages.

\section{Results}

\section{Differential bone marrow counts.}

The results of differential bone marrow counts in standard rats at successive intervals after colchicine injection are listed in Table 3. Myelogram of normal bone marrow of standard rats is shown in Figure 3. It is seen from the table that proportions of the cells of the erythrocytic series tended to decrease after the injection of colchicine in a dose of $0.10 \mathrm{mg}$ per $100 \mathrm{~g}$ body weight. This resulted in an relative increase in proportions of the cells of the granulocytic series (that is, an increase in the granulocyticerythrocytic ratios). As will be reported elsewhere, colchicine producted a marked reduction in number of the cells of the erythrocytic 


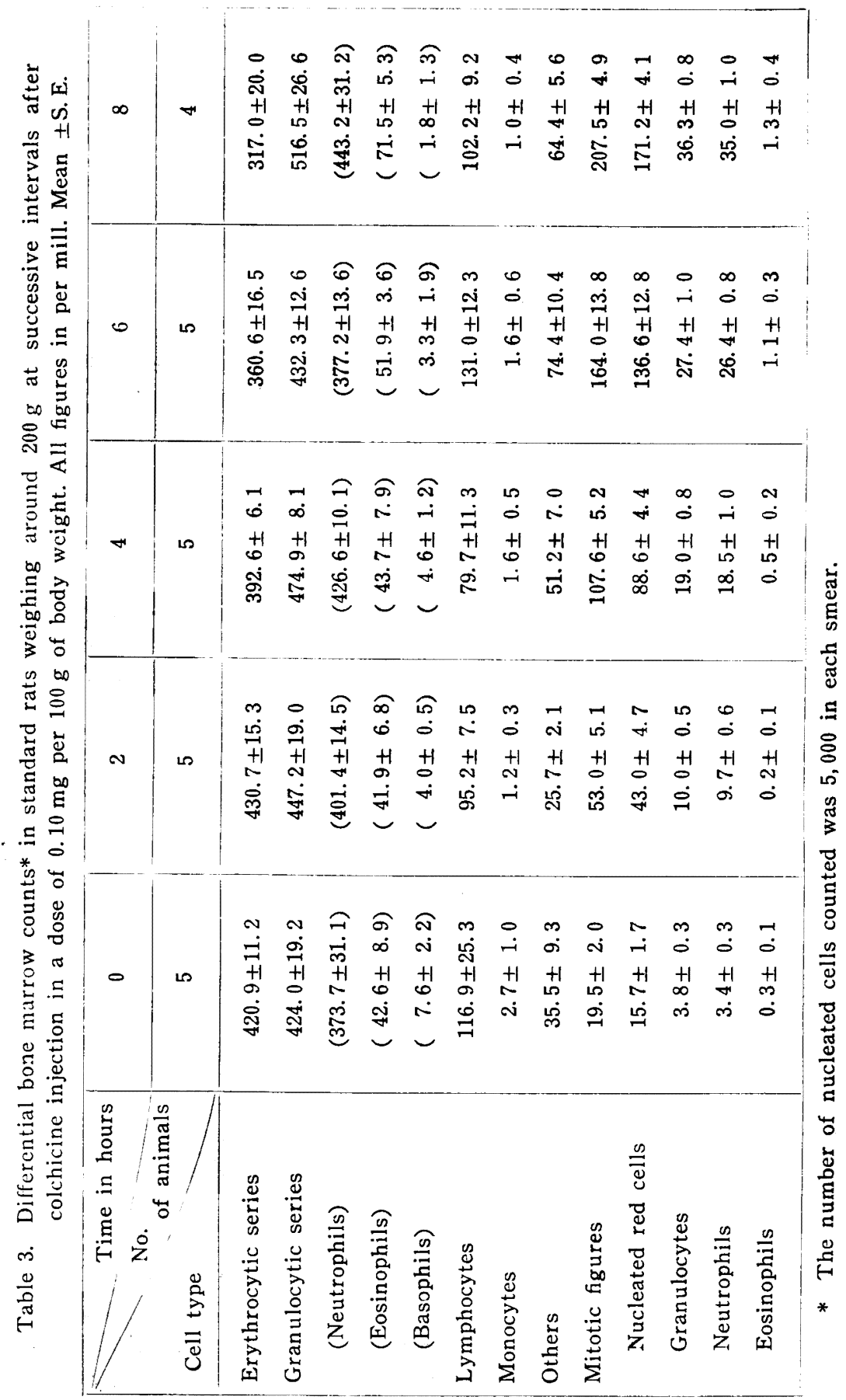




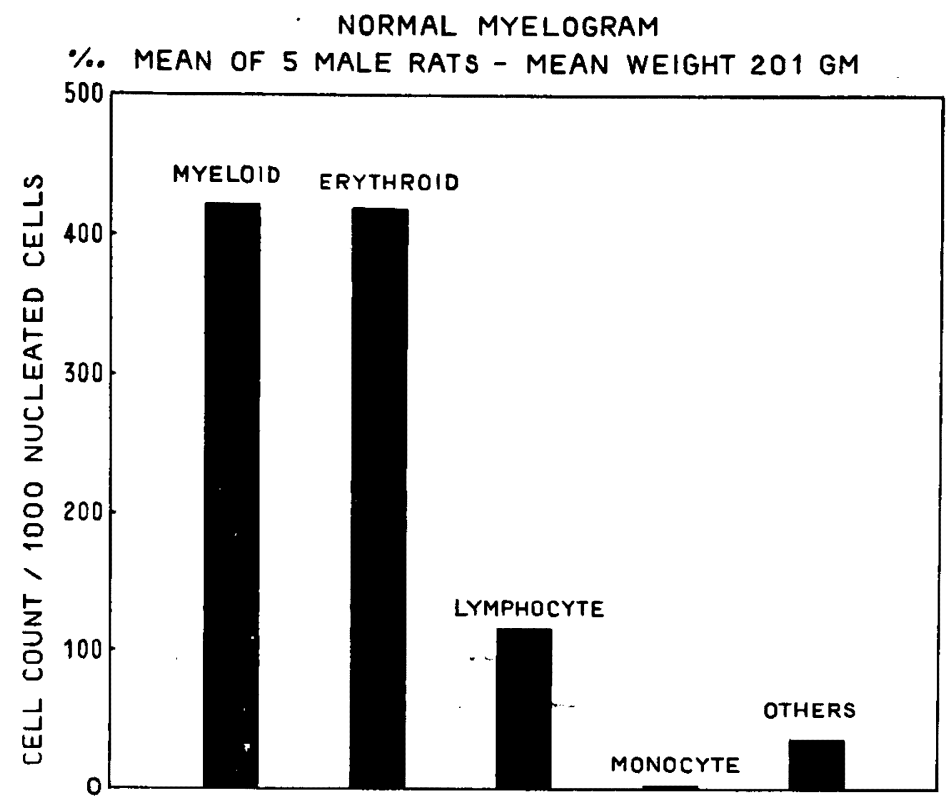

Fig. 3. Myelogram of normal bone marrow of standard rats.

series when injected in this dosage. There was no remarkable numerical changes in the other types of cells.

After colchicine injection there was a progressive accumulation of metaphases as shown in Table 4.

2. The mitotic rates of the nucleated red cells and granulocytes.

Normal values of the mitotic index were found to be: for the erythrocytic series $15.7 \pm 1.7$ per thousand nucleated marrow cells and $36.1 \pm 2.8$ per thousand nucleated red cells; and for the granulocytic series $3.8 \pm 0.3$ per thousand nucleated marrow cells and $8.9 \pm 1.1$ per thousand granulocytes $(14.8 \pm 2.4$ per thousand nonsegmented granulocytes).

The changes in values of the mitotic index obtained for both series of cells after colchicine injection are given in Table 5 . It should first be noticed that there was an almost linear increase in the number of mitoses per thousand nucleated cells of the respective serics (Figs. 4 and 5). Another finding upon which the author wishes to lay a great stress is that the most actively proliferating cells are polychromatic erythroblasts in the erythrocytic series and 


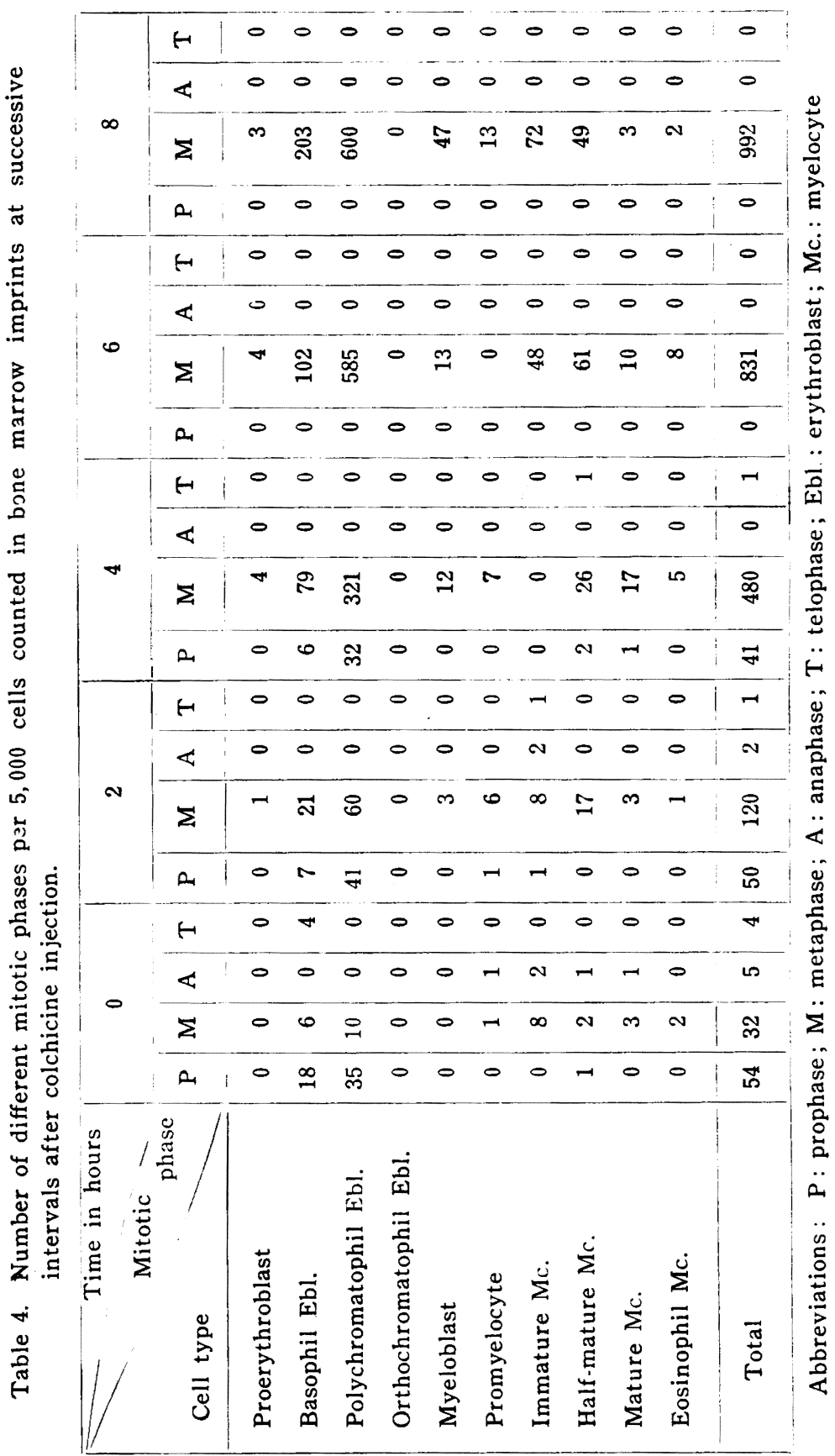


Rate of Cell Production in Bone Marrow

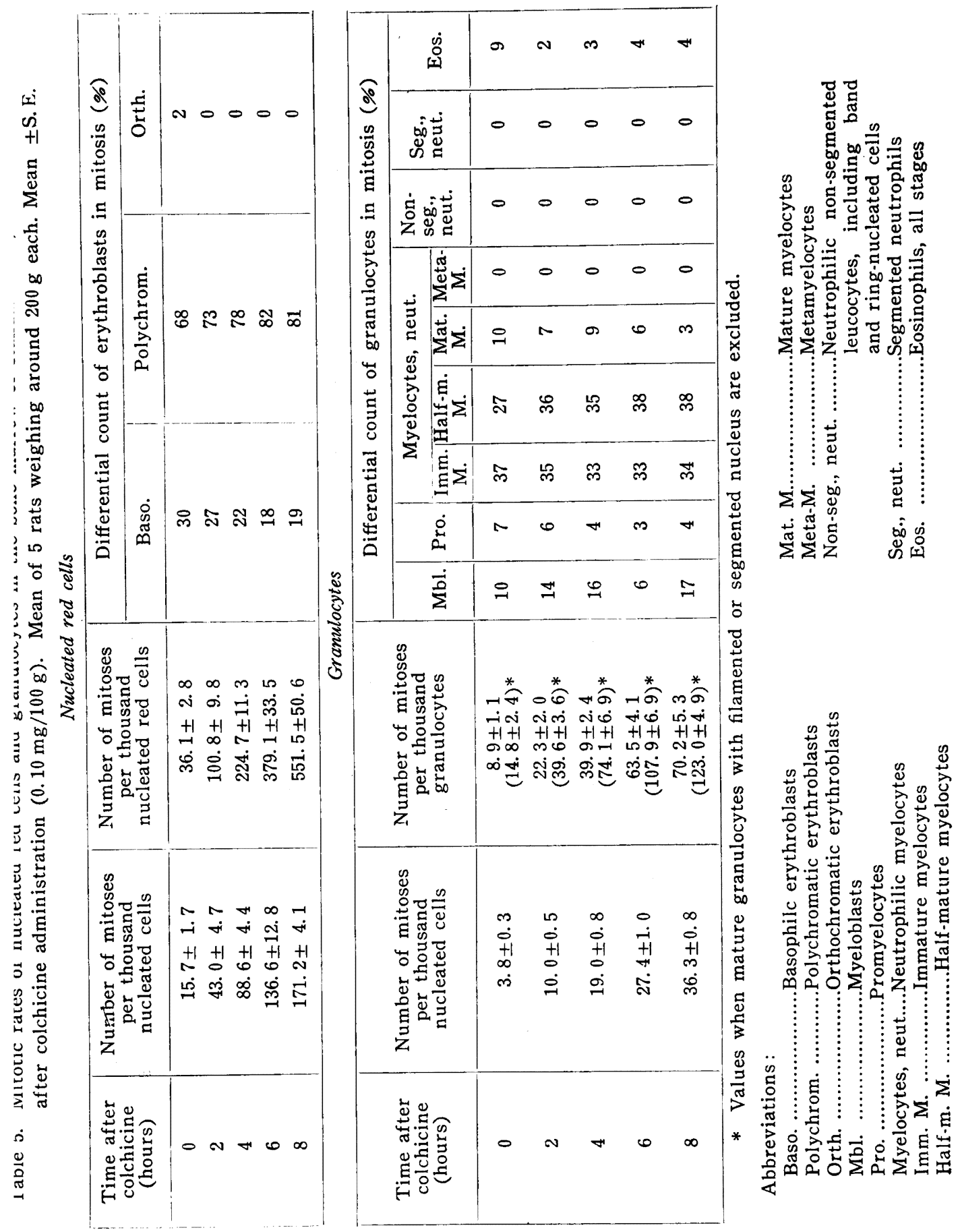




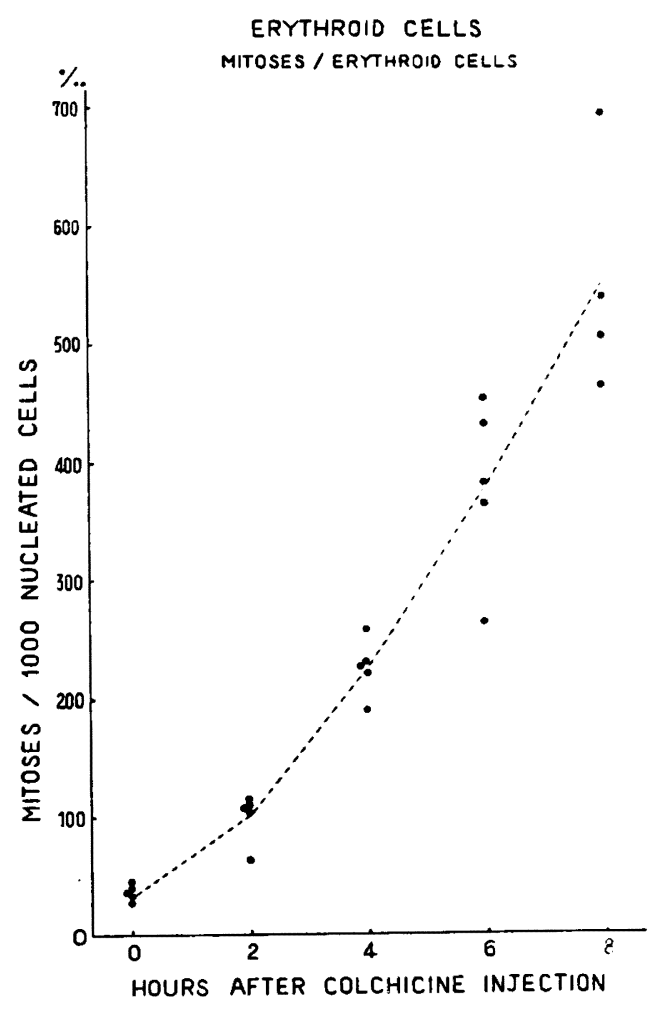

Fig. 4. Number of mitotic figures per thousand nucleated red cells in the bone marrow of standard rats, at successive intervals after colchicine injection.

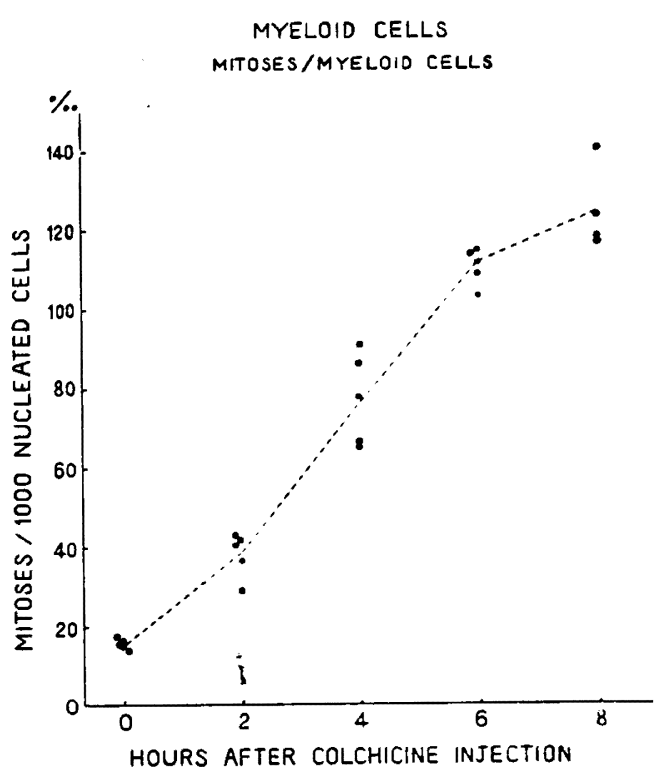

Fig. 5. Numbers of mitotic figures per thousand granulocytes in the bone marrow of standard rats, at successive intervals after colchicine injection.

immature and half-mature neutrophilic myelocytes in the granulocytic series (Figs. 6 and 7). Either orthochromatic erythroblasts or metamyelocytes do not appear to divide normally.

It is also noteworthy that at 8 hours after colchicine injection, many of the arrested metaphases, especially those of the erythrocytic series, were undergoing degeneretion by nuclear pyknosis and a few of them by nuclear fragmentation (Fig. 8). In this connection, it is of interest to note that beyond a 6 -hour period the effect of colchicine appeared to be weakened to a considerable extent, so far as the cells of the granulocytic series are concerned (see Fig. 5). This was not the case in the erythrocytic series, however, probably because colchicine produced a marked reduction in number of nondividing cells of this series, as already stated. 


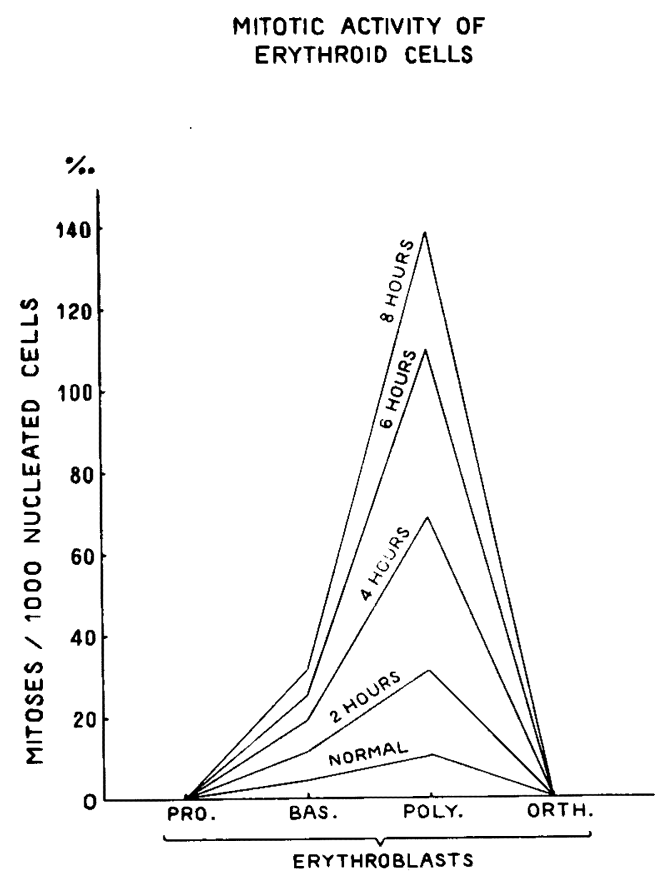

Fig. 6. Mitotic activity of erythroblasts at different stages of maturation, from 0 to 8 hours after colchicine in. jection.

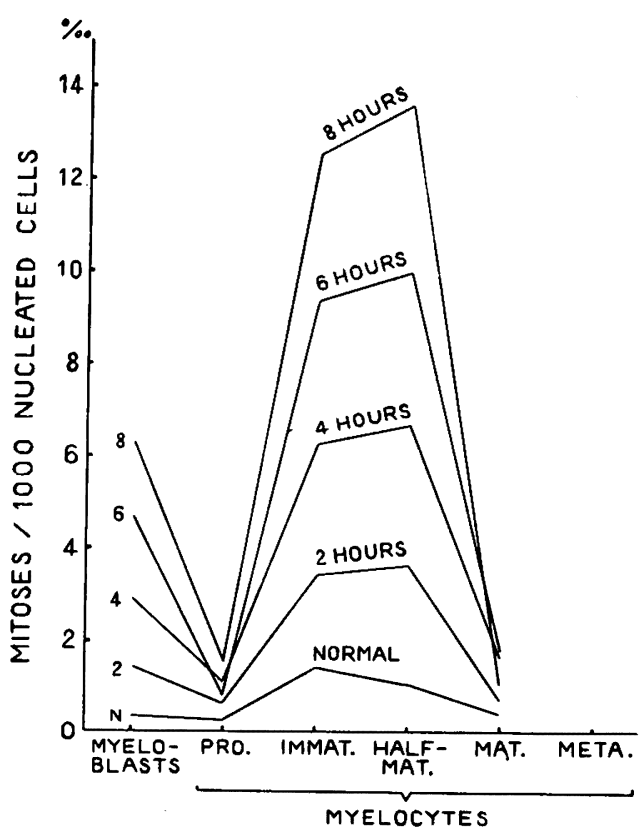

Fig. 7. Mitotic activity of myelocytes at different stages of maturation, from 0 to 8 hours after colchicine injection.

Taking these facts in consideration. it was decided to use the data of colchicine treatment for a 4 -hour period and of those for a 6 -hour period for the calculation of daily mitotic rates.

\section{The blood cell reserve in the bone marrow.}

It would be of interest to calculate the ratio of the total number of nucleated cells of each series to the total number of blood corpuscles of the corresponding series present in the general circulation, for such ratio appears to indicate the amount of blood cell reserve in the bone marrow. Using the data of total number of nucleated cells in the bone marrow of standard rats previously reported by A w a y a et al. (1960) and the results of bone marrow differential counts given in Table 4, the number of nucleated cells of each type of blcod cells within the whole bone marrow was 


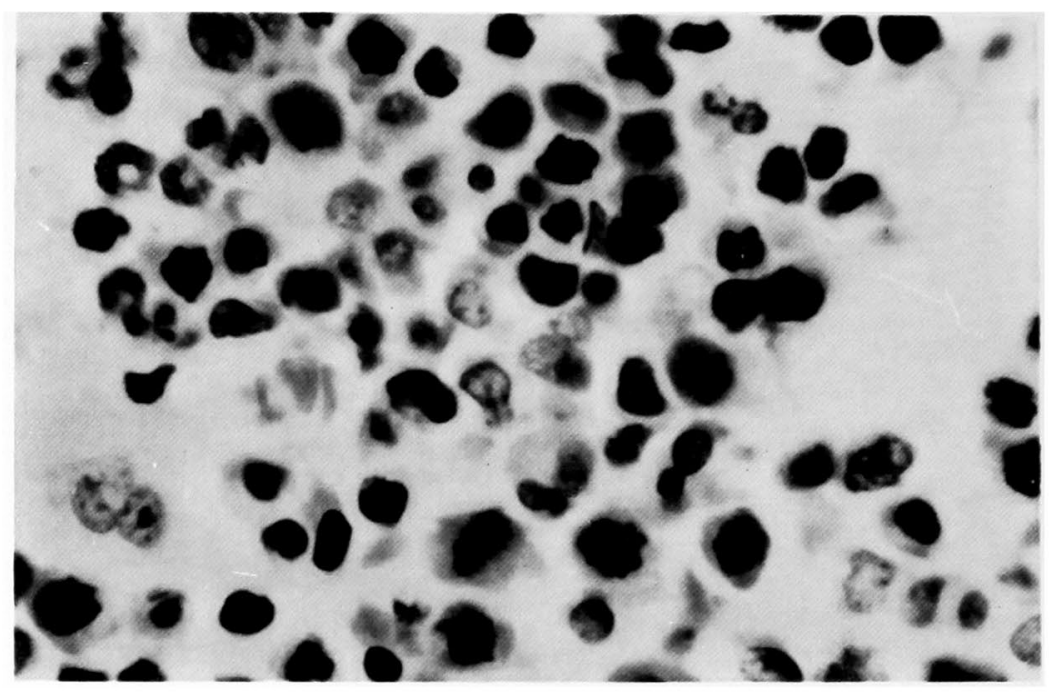

Fig. 8. Accumulation of numerous mitotic figures (metaphases) in the bone marrow, 8 hours after colchicine injection. Section from the femoral marrow. Notice almost all the erythroblasts are in mitosis.

computed. When the values obtained for the bone marrow are contrasted with the corresponding values for the circulating blood estimated by M o n d e n (1951).* the following figures may be obtained

Table 6. Blood cell reserve in bone marrow: ratio of the total nucleated cells of the respective series in marrow to the total circulating blood corpuscles in standard rats. Mean $\pm \mathrm{S}$. E.

\begin{tabular}{|c|c|c|c|}
\hline Cell type & $\begin{array}{l}\text { Total number of } \\
\text { nucleated cells } \\
\text { in marrow } \times 10^{6}\end{array}$ & $\begin{array}{l}\text { Total number of } \\
\text { corpuscle in blood* } \\
\times 10^{6}\end{array}$ & $\begin{array}{c}\text { Ratio } \\
\text { Marrow : Blood }\end{array}$ \\
\hline Total nucleated cells & $5,840 \pm 161 * *$ & & \\
\hline Erythrocytic series & $2,458 \pm 133$ & $114,400 \pm 9,380$ & $1: 47$ \\
\hline $\begin{array}{l}\text { Granulocytic series } \\
\text { (Total granulocytes) }\end{array}$ & $2,476 \pm 180$ & $48.5 \pm 6.1$ & $51: 1$ \\
\hline Neutrophils & $2,183 \pm 236$ & $46.7 \pm 5.6$ & $47: 1$ \\
\hline Eosinophils & 249. $0 \pm 58.8$ & $1.75 \pm 0.45$ & $142: 1$ \\
\hline Lymphocytes & $682.8 \pm 16.7$ & 132. $0 \pm 12.0$ & $5: 1$ \\
\hline Monocytes & $15.7 \pm 6.5$ & $7.96 \pm 1.06$ & $2: 1$ \\
\hline
\end{tabular}

* Cited from the results of $\mathrm{M}$ on de $\mathrm{n}$ (1959).

** Cited from the results of A w a y et al. (1960).

* Mean of 50 standard rats. 
as the ratios between bone marrow and blood: 1:47 for the erythrocytic series, $51: 1$ for the granulocytic series, $47: 1$ for the neutrophils, 142:1 for the eosinophils, 5:1 for the lymphocytes, and $2: 1$ for the monocytes (cf. Table 6).

It is of particular interest that the granulocytic cell reserve within the whole bone marrow was estimated to be about 50 times as great as the number of total granulocytes present in the circulating blood, whereas the total number of nucleated red cells within the whole marrow was found to be as small as about $1 / 50$ th of the total number of erythrocytes present in the circulating blood.

It has been pointed out that there is an abundant myeloid cell reserve within the bone marrow. According to Y offey (1956) who made an extensive quantitative study of bone marrow of guinea-pigs, especially the lymphocyte content therein, the granulocyte reserve in the bone marrow is about 100 times the number of granulocytes present in the blood.

As regards the lymphocyte population of bone marrow, our data indicated that the total bone marrow of standard rats contain 5 times as many lymphocytes as are present in the circulating blood (cf. Table 6). Similar quantitative data by Y of fe y (1956) on the lymphocyte content of bone marrow of guinea-pigs demonstrated that the lymphocyte population of normal marrow is 23 times as great as that of the blood.

\section{The total number of mitoses per day of each type of blood cells in the whole marrow.}

On the basis of the results obtained thus far, the total number of mitoses of each type of blood cells per 24 hours in the whole marrow may easily be calculated. The results of calculations based on colchicine treatment either for a 4-hour period or for a 6-hour period are summarized in Table $7 .^{*}$ Here, special attention was directed to the number of mitoses of the late forms of bone marrow elements, because only the late forms, such as polychromatic and orthochromatic erythroblasts in the erythrocytic series and halfmature and mature myelocytes in the granulocytic series, are considered to be the direct supply source of circulating blood cells. In contrast, the early forms, such as proerythroblasts and basophilic

* Diurnal variation in mitotic rates in the bone marrow was not taken into consideration in the present study. Concerning such variation further investigation is required. 


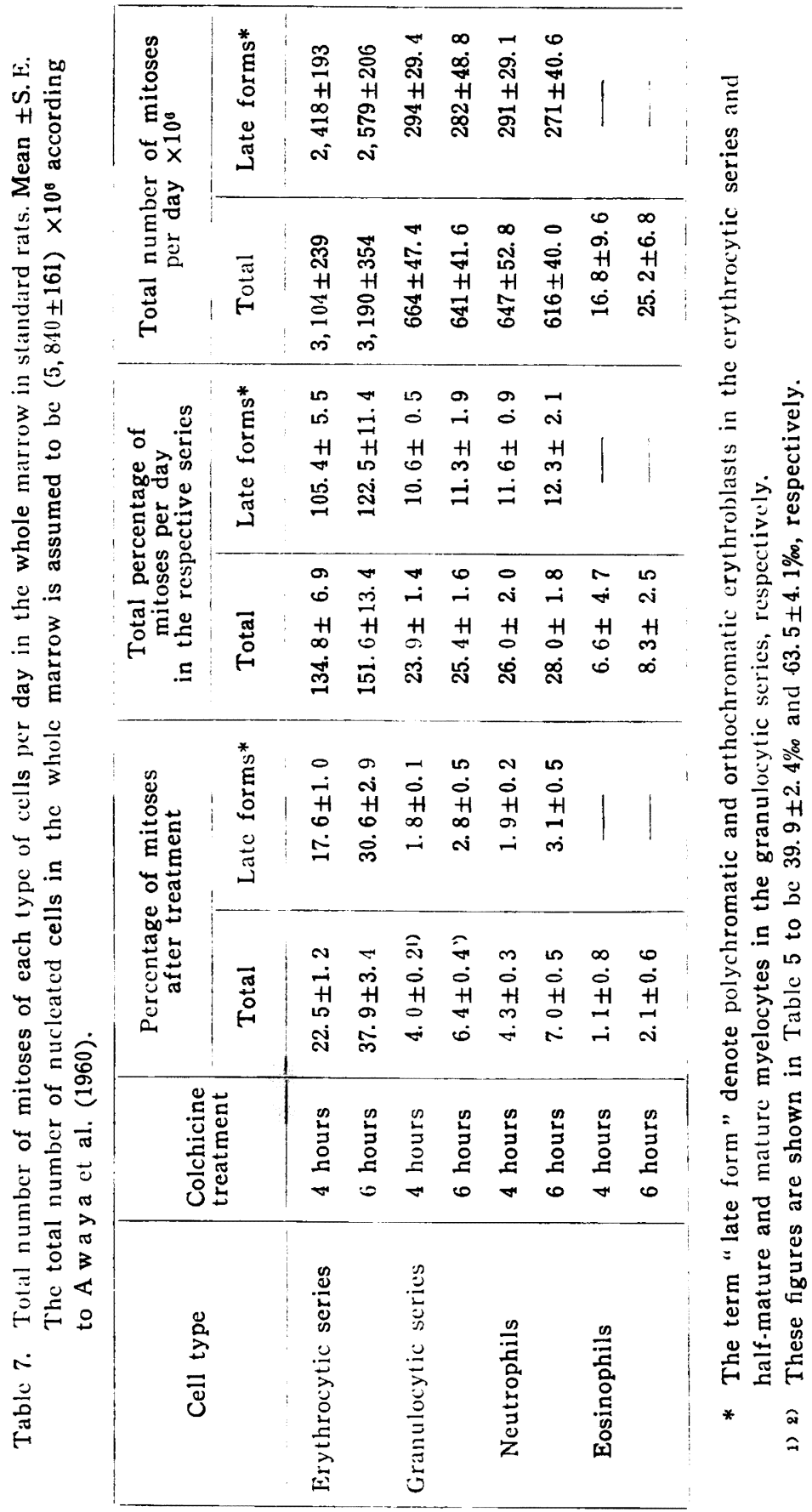


erythroblasts in the erythrocytic series and myeloblasts, promyelocytes and immature myelocytes in the granulocytic series, are thought to be the cells from which the late forms of bone marrow elements arise.

\section{The turnover time of each type of blood cells.}

The principal objective of the present study is to calculate the time taken for the replacement of a number of cells equal to that in the whole population (turnover time) with respect to each type of blood cells. Since the total cellular numbers in the blood and bone marrow and the total number of mitoses per day in the bone marrow are known, the turnover time of each type of cells may easily be calculated. The results of calculations are given in Table 8 , together with the values for the "Daily Replacement Factor" of $\mathrm{Y}$ of f e y (1954).*

One of the assumptions upon which our calculations are based is that all the blood cells newly produced by mitoses enter into the

Table 8. Estimated values for turnover time and "Daily Replacement Factor" of each type of blood cells in the blood and blood-forming tissues.

\begin{tabular}{|c|c|c|c|c|}
\hline \multirow{2}{*}{ Cell population } & \multicolumn{2}{|c|}{ Turnover time in days } & Daily Replacement Factor \\
\cline { 2 - 5 } & Total1 & Late forms & Total & Late forms \\
\hline Blood & & & & \\
Total granulocytes & $0.073-0.076$ & $0.165-0.169$ & $13.2-13.6$ & $5.9-6.1$ \\
Neutrophilis & $0.072-0.076$ & $0.161-0.172$ & $13.2-13.9$ & $5.8-6.2$ \\
Eosinophils & $0.069-0.104$ & $0.125-0.250$ & $9.0-14.4$ & $4.0-8.0$ \\
Erythrocytes & $36-37$ & $44-47$ & $0.026-0.028$ & $0.021-0.022$ \\
Bone Marrow & & & & \\
Total granulocytes & $3.94-4.19$ & & & \\
Neutrophils & $3.3)^{*}$ & & & \\
Eosinophils & $(1.9)^{*}$ & & & \\
Nucleated red cells & $0.66-0.74$ & & & \\
\hline
\end{tabular}

1 Calculated on the basis of the total number of mitoses per day.

2 Calculated on the basis of the number of mitoses of the late forms per day.

* Turnover time when mature granulocytes with filamented or segmented nucleus are excluded.

* This factor indicates how many times the cell population in the blood are daily replaced by the newly formed cells; it is expressed as the reciprocal of the turnover time in days. 
general circulation through the normal process of cell maturation. Strictly speaking, this assumption is not correct. Since, as already mentioned, only the late forms of bone marrow elements may be regarded as being the direct supply source of the circulating blood cells, the calculation of the turnover times of cell populations in the circulating blood should be based on the number of mitoses per day of the late forms alone, substracting the number of mitoses of the early forms (such as proerythroblasts, basophilic erythroblasts, myeloblasts, promyelocytes and immature myelocytes) from the total number of mitoses per day.

Thus, the turnover times of cell populations in the blood were estimated to be : $0.165-0.169$ day for the total granulocytes; 0.161 0.172 day for the neutrophils; $0.125-0.250$ day for the eosinophils; and 44-47 days for the erythrocytes. The values of the "Daily Replacement Factor" of $\mathrm{Y}$ of $\mathrm{fe} \mathrm{y}$ were as follows : 5.9-6.1 for the total granulocytes; 5.8-6.2 for the neutrophils; $4.0-8.0$ for the eosinophils; and 0.021-0.022 for the erythrocytes. It should be emphasized here that the total number of granulocytes newly produced by mitoses per day in the whole marrow was estimated to be about 13 times, and that of granulocytes entering per day into the blood to be about 6 times, as great as the number of granulocytes present in the blood; whereas the daily replacement factor for the erythrocytes was exceedingly smaller and found to be in the order of 0.03 or 0.02 .

The turnover times of cell populations in the bone marrow were calculated to be: $3.94-4.19$ days for the total granulocytes; 3.56-3.84 days for the neutrophils; $12-15$ days for the eosinophils; and 0.66-0.74 day for the nucleated red cells. When mature granulocytes with filamented or segmented nucleus are excluded, the turnover of the total granulocytes turns out to be 2.3 days and that of the neutrophils to be 1.9 day. From the results obtained, it is seen that the nucleated red cells is being most rapidly renewed. This deserves special attention.

\section{The mitotic time of dividing cells in the bone marrow.}

The duration time of mitosis may be estimated by the colchicine method, using Dustin's formula:

$$
\mathrm{A}=\frac{\mathrm{M} \cdot \mathrm{t}}{\mathrm{X}}
$$

where A equals the calculated duration of mitosis, $M$ is the original 
mitotic index, and $\mathrm{X}$ is the observed mitotic index after $\mathrm{t}$ hours of exposure to colchicine. The figures obtained are given in Table 9.

Table 9. Values of the mitotic time of dividings cells in the bone marrow estimated af the exposure to colchicine from 2 to 8 hours.

\begin{tabular}{|c|c|c|}
\hline $\begin{array}{c}\text { Time of exposure to } \\
\text { colchicine in hours }\end{array}$ & $\begin{array}{c}\text { Nucleated red cells } \\
\text { (hour) }\end{array}$ & Granulocytes (hour) \\
\hline $2(0-2)$ & 0.72 & $0.75(0.79 *)$ \\
$2(2-4)$ & 0.89 & $1.07\left(1.12^{*}\right)$ \\
$4(0-4)$ & 0.64 & $0.80(0.89 *)$ \\
$4(2-6)$ & 1.06 & $1.47\left(1.42^{*}\right)$ \\
$6(0-6)$ & 0.57 & $0.82(0.84 *)$ \\
$6(2-8)$ & 1.09 & $1.92(1.90 *)$ \\
$8(0-8)$ & 0.52 & $0.96\left(1.01^{*}\right)$ \\
\hline
\end{tabular}

* Mature granulocytes with filamented or segmented nucleus are excluded.

As seen from the table, the mitotic time varies around one hour, with a relatively narrow range between 0.57 and 1.92 hour. There was no appreciable difference in the mitotic time between the cells of the erythrocytic series and those of the granulocytic ones. The colchicine method is originally based on the assumption that cells are permitted to enter mitosis but all mitoses are arrested at the metaphase, after the chemical is administered. Strictly speaking, however, this is not the case, probably due to the toxic action of the drug on resting and dividing cells. Namely, in most instances the rate of entrance of cells into mitosis is somewhat diminished and, in addition, not all the mitosis are blocked at the metaphase. Consequently, the values of the mitotic time estimated by the colchicine method tend to be greater than those obtained by other methods ( $\mathrm{L}$ u s h ba $\mathrm{g} \mathrm{h}, 1956$ ). Considering these facts, the author assumed the average mitotic time of dividing cells to be about one hour. In the preceding studies on the rate of cell production in the thymolymphatic organs, Ito (1959) also assumed the mitotic time of dividing cells of the lymphoid series to be about one hour. Besides, the author considered a mitotic cycle of 30-minute duration to be also possible for the cells of both the erythrocytic and the granulocytic series.

If the mitotic time (MT) and the mitotic index (MT) are known, the intermitotic time (IT) of tissue cells can be calculated from $\mathrm{H}$ of $\mathrm{f} \mathrm{m}$ a n's formula ( $\mathrm{H}$ of $\mathrm{f} \mathrm{m}$ a $\mathrm{n}, 1953$ ): 


$$
\mathrm{IT}=\mathrm{MT} / \mathrm{MI} \text {. }
$$

Using the figures for the mitotic index before colchicine injection that are given in Table 5 and assuming the mitotic time to be 1-hour or 30-minute duration, the intermitotic times of cell populations in the bone marrow were then calculated. The figures obtained are shown in Table 10, together with the corresponding values estimated by the colchicine method. Here, it should be noticed that the turnover time is approximately equal to the intermitotic time. Strictly speaking, the turnover time is the sum of of the intermitotic time plus the mitotic time. However, the mitotic time is only a small fraction of the intermitotic time and may therefore be neglected.

Table 10. Values of the turnover or intermitotic time of cell populations in the bone marrow.

\begin{tabular}{|c|c|c|c|}
\hline \multirow[b]{2}{*}{ Cell population } & \multirow[b]{2}{*}{$\begin{array}{l}\text { Direct method } \\
\text { (colchicine method) }\end{array}$} & \multicolumn{2}{|c|}{ Indirect method* } \\
\hline & & $\begin{array}{l}\text { 1-hours duration } \\
\text { of minosis }\end{array}$ & $\begin{array}{c}30 \text {-minute } \\
\text { duration of } \\
\text { mitosis }\end{array}$ \\
\hline Nucleated red cells & $0.66-0.74$ day & 1. 17 day & 0.58 day \\
\hline Granulocytes & $\begin{array}{l}3.94-4.19 \text { days } \\
(2.25-2.31)^{* *}\end{array}$ & $\begin{array}{l}4.66 \text { days } \\
(2.82 \text { days }) * *\end{array}$ & $\begin{array}{l}2.33 \text { days } \\
(1.41 \text { day })^{* *}\end{array}$ \\
\hline
\end{tabular}

* Assumed that the mitotic time is of 1-hour and 30-minute duration.

** Values when mature granulocytes with filamented or segmented nucleus are excluded.

It is seen from the table that the figures obtained by both the direct and indirect methods fairly well agree with each other.

\section{Discussion}

\section{The rate of mitotic activity in the bone marrow.}

The present work is an attempt to calculate the total number of blood cells newly produced by mitosis per day in the bone marrow, on the basis of quantitative determinations of mitotic rates in this organ. Consequently, the reliability of our results depends upon whether the figures of the mitotic index used for calculations are quite reasonable or not.

It is therefore of interest to compare our figures with those published by other workers. It should be first emphasized that our figures for the mitotic index of bone marrow of normal standard 
rats are in good agreement with the published figures. According to $\mathrm{J}$ a p a (1942), the mitotic index of normal human bone marrow is $1.5 \%$ for the total nucleated cells, $3.3 \%$ for the nucleated red cells, and $1.0 \%$ for the granulocytes; and according to $\mathrm{R}$ o $\mathrm{h} \mathrm{r}(1949)$, it is $1.0-4.2 \%$ for the nucleated red cells and $0.6-1.1 \%$ for the granuloblasts. ${ }^{*}$ In their recent study on normal human bone marrow, Fliedner et al. (1959) estimated the mitotic index to be $0.9 \%$ for the total nucleated cells, $2.24 \%$ for the nucleated red cells ( $4 \%$ for the nucleated red cells capable of cell division**) and $2.0 \%$ for the granuloblasts. ${ }^{* *} \mathrm{~S}$ a ito and $\mathrm{Mi}$ y a moto (1959) also reported similar figures for normal human bone marrow; namely, $4.18 \%$ for the erythroblasts and $1.03 \%$ for the granulocytes capable of cell division. ${ }^{* * *}$ On the other hand, our figures of the mitotic index of rat bone marrow were: $1.95 \pm 0.2 \%$ for the total nucleated cells, $3.61 \pm 0.28 \%$ for the nucleated red cells and $0.89 \pm 0.11 \%$ for the granulocytes $(1.48 \pm 0.24 \%$ for the non-segmented granulocytes). As mentioned above, the mitotic index of the nucleated red cells is of the order of 2 to 4 per cent and that of the granulocytes of the order of 0.6 to 1.5 per cent.

As regards the mitotic index of rat bone marrow, relatively low figures are reported by $\mathrm{K}$ ind red (1942), who made an extensive quantitative study of bone marrow in sections, using young adult albino rats weighing approximately $200 \mathrm{~g}$. His figures were $0.8-0.9 \%$ for the total nucleated cells, $0.93 \%$ for the nucleated red cells and $0.92 \%$ for the granulocytes. As far as the granulocytes are concerned, his figure well coincides with ours. However, his figure for the erythrocytic series is exceedingly smaller than ours. This is the crucial point upon which his view on transformation of lymphocytes into erythroblasts is based, as will be mentioned later.

\section{The turnover time of the granulocytes in the blood.}

We shall next consider the rate of renewal of the granulocytes and erythrocytes in the blood. A comparison of the values for the turnover time, or intervascular life span, of the granulocytes and erythrocytes in the circulating blood estimated by different methods is shown Table 11.

\footnotetext{
* Granulocytes capable of cell division.

** The orthochromatic normoblasts that do not divide normally are excluded.

*** Granulocytes capable of cell division.

**** Calculated from the data given in the paper of S a i to and M i y a m o to (1959).
} 


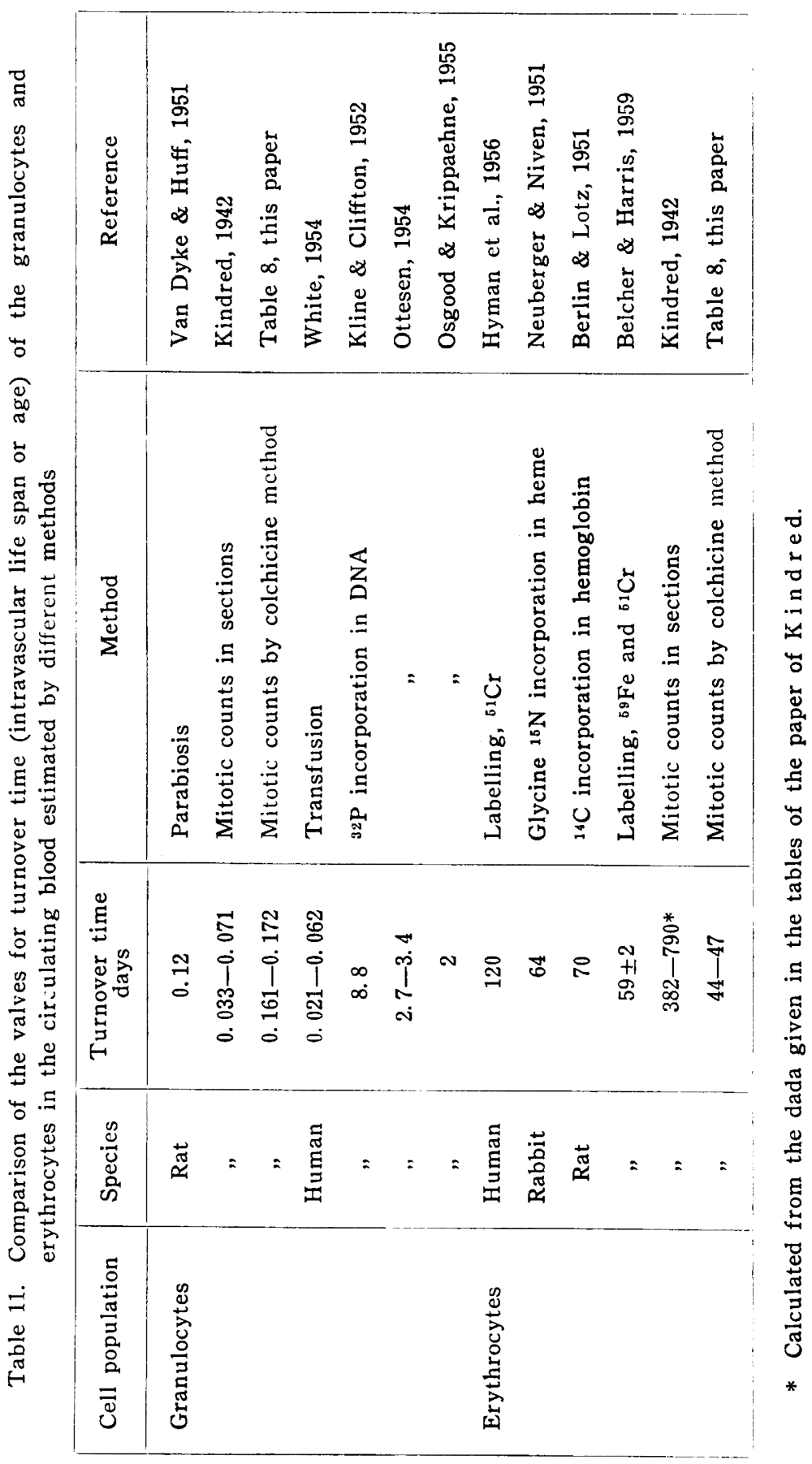


As regards the turnover time of the granulocytes in the blood, it should first be noticed that the values estimated by our method fairly well agree not only with the estimates by mitotic counts in sections ( $\mathrm{K} \mathrm{i} \mathrm{n} \mathrm{d} \mathrm{r} \mathrm{e} \mathrm{d,} \mathrm{1942),} \mathrm{but} \mathrm{also} \mathrm{with} \mathrm{those} \mathrm{based} \mathrm{on} \mathrm{survival} \mathrm{of}$ granulocytes after either parabiosis (Van D y k and $\mathrm{H} \mathrm{uff}, 1951$ ) or transfusion ( $\mathrm{Wh}$ it e, 1954), and that the figures obtained are of the order of from 0.02 to 0.2 days (from thirty minutes to 5 hours). Since, however, the estimates based on mitotic counts are thought to be more reliable than those based on survival after parabiosis or transfusion, the author consider a renewal time of $0.161-0.172$ day (about 4 hours) to be the most reasonable figure for the blood granulocytes.

Of particular interest in this connection is the fact that the values for the life span of the granulocytes* estimated by use of radioactive tracers are much greater than the above-mentioned figures. By measurement of the incorporation of ${ }^{32} \mathrm{P}$ into deoxypentose nucleic acids (DNA) of the granulocytes in man, Klin e and $\mathrm{Cl}$ if $\mathrm{ft}$ on (1952) estimated the life span of these cells in the circulating blood to be 8.8 days and the time they spend within the bone marrow as immature forms to be about 4 days. Using similar technique, Ottesen (1954) found the mean age of the granulocytes in the blood to be 8.7-9.4 days, and that the main part of the granulocytes enters the blood stream at an age of about 6 days. On the basis of in-vitro survival of human leukocytes and their DNA uptake of ${ }^{32} \mathrm{P}, \mathrm{Osgood}$ and $\mathrm{Krippaehn}$ (1955) indicated a life span of 2 day for the segmented neutrophils and a life span in the bone marrow alone of the order of 3 to 4 days; thus giving a total life span of 5-6 days for the cells of the neutrophilic series.

Similar discrepancy is also seen, with respect to the turnover time of the lymphocytes in the blood, between the values estimated by mitotic counts or cannulation of thoracic duct lymphocytes on the one hand, and the estimates based on DNA uptake of radioactive material and in-vitro survival of these cells on the other. Namely, the former methods gave a life span of about 0.3 day for the blood lymphocytes, whereas the life span of these cells estimated by the latter methods was longer than 3 days, and for the most lymphocytes

* The life span or average age of a type of cells is considered to be equal to the turnover time of the population of this type of cells. 
it was estimated to be of the order of 100 to 200 days ( 0 t t e s e n, 1954 ; H a milt o $\mathrm{n}, 1954$ and 1956).

The reason for such discrepancy in not clear. However, it may be interpreted as indicating an overproduction of both the granulocytes in the bone marrow and the lymphocytes in the thymolymphatic organs. In this connection, the claims of $\mathrm{Osgood}$ (1954) and L is s a (1956) are of particular interest that leukocytes are not primarily blood cells but are merely en route in the blood to the defense of the body, and that only a small portion of the total leukocytes outside the hematopietic organs are present in the blood stream at any one time.

At this point, it should be recalled that the total number of granulocytes newly produced by mitosis per day in the whole marrow was estimated to be about 13 times as great as the total number of granulocytes present in the circulating blood. Similarly, the results of previous investigations on the thymolymphatic organs of rats have demonstrated that in these organs lymphocytes are being produced by mitosis in numbers sufficient to replace the blood lymphocytes about 2 to 3 times daily ( $\mathrm{O}$ s o g o e et al., 1957; M o n d e n $1959 \mathrm{~b}$; I t o, 1959). In view of the fact that the true life span of the granulocyte and lymphocyte is hardly thought to be less than 24 hours, the above-mentioned findings seen to support the view that the length of the intravascular phase of the leukocytes does not represent their true life span. From such viewpoint, leukocytes cannot properly be called blood cells. It is generally believed that the extravascular pool of leukocytes is very great, far exceeding that within the vascular system.

\section{The turnover time of the erythrocytes in the blood.}

The results of estimation of the life span of the erythrocytes are in sharp contrast with those of the granulocytes. It is of essential importance that the values of the intravascular life span of the erythrocytes estimated by use of radioactive tracers are in good agreement with those estimated by mitotic counts, except for the results of mitotic counts in sections by $\mathrm{K} \mathrm{ind} \mathrm{red} \mathrm{(1942)} \mathrm{upon}$ which a brief mention will be made later. Among figures presented in Table 11, the life span of the rat erythrocytes is of especial interest; it was estimated on the basis of labelling with or incorporation of ${ }^{14} \mathrm{C},{ }^{51} \mathrm{Cr}$ or ${ }^{59} \mathrm{Fe}$ either to be 70 days (Berlin and Lotz, 1951) or to be $59 \pm 2$ days (Belcher and Harris, 1959), 
while a life span of 44-47 days was obtained by mitotic counts in the present study (cf. Table 11). Since in our calculations the presence of a large amount of erythrocytes within the bone marrow was not taken into consideration, it can be stated that both methods give quite similar results. This seems to indicate taat in erythrocytes the true life span well coincides with the intravascular life span. From this viewpoint, erythrocytes may be called blood cells in the true sense of the term.

The present findings also indicate that erythrocytes in the bone marrow of young mature rats may multiply themselves by mitosis in sufficiently great number to meet the demands of the blood, since the life span of erythrocytes estimated by mitotic counts is somewhat smaller than the estimates based on the labelling with or incorporation of ${ }^{51} \mathrm{Cr}$, ${ }^{59} \mathrm{Fe}$ or ${ }^{51} \mathrm{Cr}$. As already mentioned, $\mathrm{K}$ i $\mathrm{n} \mathrm{d} \mathrm{r} \mathrm{e} \mathrm{d}$ (1942) who made an extensive quantitative study on the rate of cell production in the hematopoietic organs in sections, obtained exceedingly low values with respect to the mitotic index of the erythroblasts in the bone marrow, that is, of the order of less than $1 \%$. This is as low as about $1 / 3 \mathrm{rd}$ of the figures obtained in man and rat by other workers including us, and the values of the turnover time of the erythrocytes calculated using the data given in the paper of $\mathrm{Kindred}$ are of the order of 400 to 800 days (cf. Table 11).

On the basis of the results mentioned above, K in d red maintains that the production of erythrocytes by mitosis in the whole marrow, when contrasted with the estimated needs of the circulating blood, is not sufficient to meet the demands of the blood, and supports the hypothesis of $J$ ordan $(1936,1939)$ that lymphocytes produced in excess are filtered off in the bone marrow to become the stem cells for the development of erythrocytes. A similar view is also maintained by $\mathrm{Y}$ offe $\mathrm{y}(1954,1955,1956,1958)$, who is making a close quantitative examination of the lymphocytes in the bone marrow of guinea-pigs. The present findings do not favor such view, however. It should again be emphasized here that in the bone marrow mitotic figures of erythroblasts occur in sufficiently great numbers when contrasted with the demands of the blood. There is no necessity for assuming that the erythroid population of the bone marrow must receive from some outside source in order to produce sufficient erythrocytes to meet the demands of the blood. 


\section{The turnover times of the granulocytes and nucleated red cells in the bone marrow.}

As seen in Table 8, the turnover times of cell populations in the bone marrow were estimate to be of the order of 4 days for the granulocytes and less than 24 hours for the nucleated red cells. On the basis of measurements of incorporation of radioactive material (e.g., ${ }^{32} \mathrm{P}$ ) into DNA of the granulocytes, on the other hand, the turnover time of these cells in the bone marrow was estimated by Kline and $\mathrm{Cl}$ iffton (1952) to be 4 days, by $\mathrm{Osgood}$ and $\mathrm{Kr}$ i p pa e hne (1955) to be 3-4 days and by $\mathrm{O}$ t e se $\mathrm{n}$ to be 5-6 days in man. It is of particular interest that the figure estimated by mitotic counts well coincides with the corresponding values estimated by use of radioactive material. As already stated, this was not the case as far as the turnover time of the granulocytes in the blood is concerned.

\section{Summary}

1. In an attempt to make possible a direct calculation of the total number of cells newly produced by mitosis per day in the bone marrow, a series of determinations have been made of the mitotic index of bone marrow of young mature male albino rats weighing around $200 \mathrm{~g}$, before and at successive intervals after the subcutaneous injection of colchicine in a dose of $0.10 \mathrm{mg}$ per $100 \mathrm{~g}$ of body weight.

2. Normal values of the mitotic index of bone marrow were found to be for the erythrocytic series $36.1 \pm 2.8$ per thousand nucleated red cells and for the granulocytic series $8.9 \pm 1.1$ per thousand granulocytes $(14.8 \pm 2.4$ per thousand non-segmented granulocytes).

3. The total percentages of mitoses per day were estimated to be $134.8-151.6 \%$ for the erythrocytic series, $23.9-25.4 \%$ for the total granulocytes, $26.0-28.0 \%$ for the neutrophils and $6.6-8.3 \%$ for the eosinophils; whereas the corresponding figures for the late forms alone were $105.4-122.5 \%$ for the erythrocytic series, $10.6-11.3 \%$ for the total granulocytes, and $11.6-12.3 \%$ for the neutrophils.

4. Using the data of A w a a et al. (1960) on the total number of nucleated cells in the whole marrow, the average numbers of mitoses per day were computed to be $(3,104-3,190) \times 10^{6}$ for the erythrocytic series, $(641-664) \times 10^{6}$ for the total granulocytes, (614- 
$547) \times 10^{6}$ for the neutrophils, and $(16.8-25.2) \times 10^{6}$ for the eosinophils When mitoses of the late forms alone were taken into accunt, the corresponning figures turned out to be $(2,418-2,579) \times 10^{6}$ for the erythrocytic series, $(287-294) \times 10^{6}$ for the total granulocytes, and $(271-291) \times 10^{6}$ for the neutrophils.

5. On the basis of an assumption that only the late forms of bone marrow elements are the direct supply source of the circulating blood cells and using the data of M o n de $n(1959 \mathrm{~b})$ on total cellular numbers in the blood, the turnover times of cell populations in the blood were calculated to be $0.165-0.169$ day (about 4 hours) for the total granulocytes, 0.161-0.172 day for the neutrophils, 0.125-0.250 day for the eosinophils, and 44-47 days for the erythrocytes.

6. By a direct calculation from the figures obtained for the daily mitotic rates, the turnover time of each type of blood cells in the bone marrow was estimated to be 3.94-4.19 days for the total granulocytes (2.3 day for the non-segmented granulocytes), 3.56-3.84 days for the neutrophils (1.9 days for the non-segmented neutrophils), 12-15 days for the eosinophils, and 0.66-0.74 day for the nucleated red cells.

7. Besides, an indirect calculation of the turnover times of cell populations in the bone marrow was also made from $\mathrm{H}$ of $\mathrm{f}$ man's formula, assuming that the mitotic time of dividing cells is of 1-hour or of 30 -minute duration.

\section{References}

A w a y, K., H. F u ji i, Y. T a n a ka, and M. Ok a d a 1960. Estimation of total number of nucleated cells in the bone marrow of young adult albino rats. Arch. hist. jap., 18: 473-477.

B e $1 \mathrm{cher}$, E. H., and E.B. H a r r is 1959. Studies of red cell life span in the rat. J. Physiol., Lond., 146: 217-234.

Berlin, N.I., and C. L ot $z$ 1951. Life span of the red blood cells of the rat following acute hemorrhage. Proc. Soc. exp. Biol. Med., N. Y., 79: 788-790.

Fliedner, T.M., E.P. Cronkit e, V.P. Bond, J.R. Rubini, and G. Andrews 1959. The mitotic index of human bone marrow in healthy individuals and irradiated human beings. Acta haemat., 22: 65-78.

Hamilton, L. D. 1954. Nucleic acid metabolism in chronic lymphatic leukemia. J. clin. Invest., 33 : 939-940.

H a milto n, L. D. 1956. Nucleic acid turnover studies in human leukemic cells and the function of lymphocytes. Nature, 178: 597-599.

Hof $f \mathrm{~m}$ a n, J.G. 1953. The Size and Growth of Tissue Cells. Charles C. Thomas, Spring field, Ill. 
I t o, H. 1959. Quantitative studies on the rate of cell production in the thymolymphatic organs. II. Estimation of the daily mitotic activity in young adult albino rats. Okajimas Fol. anat. jap., 34: 13-25.

J a pa, J. 1942. A study of the mitotic activity of normal human bone marrow. Brit. J. exp. Path., 23 : 272-276.

Jordan, H.E. 1936. The relation of lymphoid tissue to the process of blood production in the bone marrow. Am. J. Anat., 59: 249-297.

J orda n, H. E. 1939. The lymphocytes in relation to erythrocyte production. Anat. Rec., 73: 227-241.

K in d red, J.E. 1938. A quantitative study of the lymphoid organs of the albino rat. Am. J. Anat., 62: 453-473.

$\mathrm{K}$ indred, J.E. 1940. A quantitative study of the hematopoietic organs of young albino rats. Am. J. Anat., 67: 99-149.

K ind red, J.E. 1942. A quantitative study of the hematopoietic organs of young adult albino rats. Am. J. Anat., $71: 207-243$.

Kline, D. L., and E.E. Clif $\mathrm{t}$ on 1952. The life span of leukocytes in the human. Science, 115: 9-11.

L is s a c, J. 1957. La durée de vie de leucocytes. Rev. franç, Et. clin. biol., 2: 178196.

Lushaugh, C.C. 1956. Morphologic methods of determining cellular doubling times: a review. J. Histochem., $4: 499-507$.

Monden, Y. 1959a. Quantitative evaluation of total cellular number and cellular density in the thymolymphatic organs of young adult albino rats by means of DNA determination. Okajimas Fol. anat. jap., 32: 193-206.

Monden, Y. 1959b. A quantitative study of cell populations in the circulating blood of young adult albino rats. Okajimas Fol. anat. jap., 32: 207-213.

Os good, E. E. 1954. Number and distribution of human hemic cells. Blood, 9: 1141-1154.

Osgood, E.E., and M. L. Krippaehne 1955. Comparison of the life span of leukemic and non-leukemic neutrophils. Acta. haemat., 13: 153-160.

Osogoe, B., Y. Monden, and H. I to 1957. Étude quantitative de la production cellulaire par le système thymo-lymphatique du rat. Sang, 28: 729-737.

$\mathrm{O}$ s o g o e, B, and K. A w a y a 1957. Turnover of cell populations in blood and bloodforming tissue. Acta haemat. jap., 21, Suppl.: 408-418.

Ottesen J. 1954. On the age of human white cells in peripheral blood. Acta physoil. scand., 32: 75-93.

Saito, A., and T. Mi y a moto 1959. The pattern of hematopoiesis in the bone marrow. Report I. Monophasic mitosis in the erythropoietic system and diphasis in the leucopoietic system. Acta haemat. jap., 22: 1-11.

$\mathrm{V}$ a n D y ke, D. C., and R. L. H u f 1 1957. Life span of white blood cells as measured in irradiated parabiotic rats. Am. J. Physiol., 165: 341-347.

White, L. P. 1954. The intravascular life span of transfused leukocytes tagged with atabrine. Blood, 9: 73-82.

Y of f e y, J. M. 1954. Bone marrow. Brit. med. J., 1954, Vol. 2: 193-204.

$\mathrm{Y}$ of $\mathrm{fey}, \mathrm{J} . \mathrm{M}$. 1956. The mobilization and turnover times of cell population in blood and blood-forming tissue. J. Histochem. Cytochem., 4: 516-530.

Y of f e y, J.M., G. A. H a n ks, and L. Kelle y 1958. Some problems of lymphocyte production. Ann. N. Y. Acad. Sci., 73, Art. 1: 48-78. 


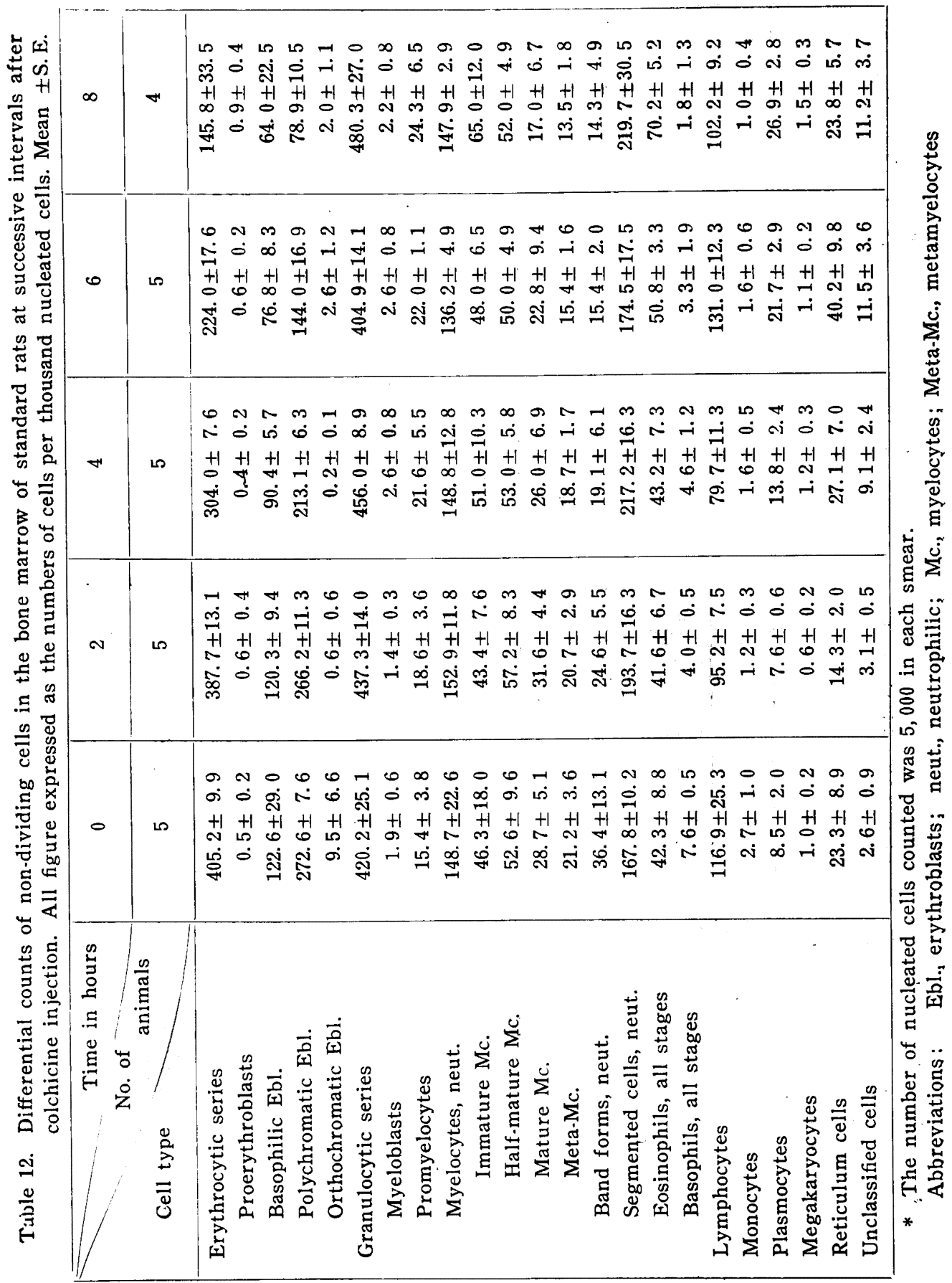




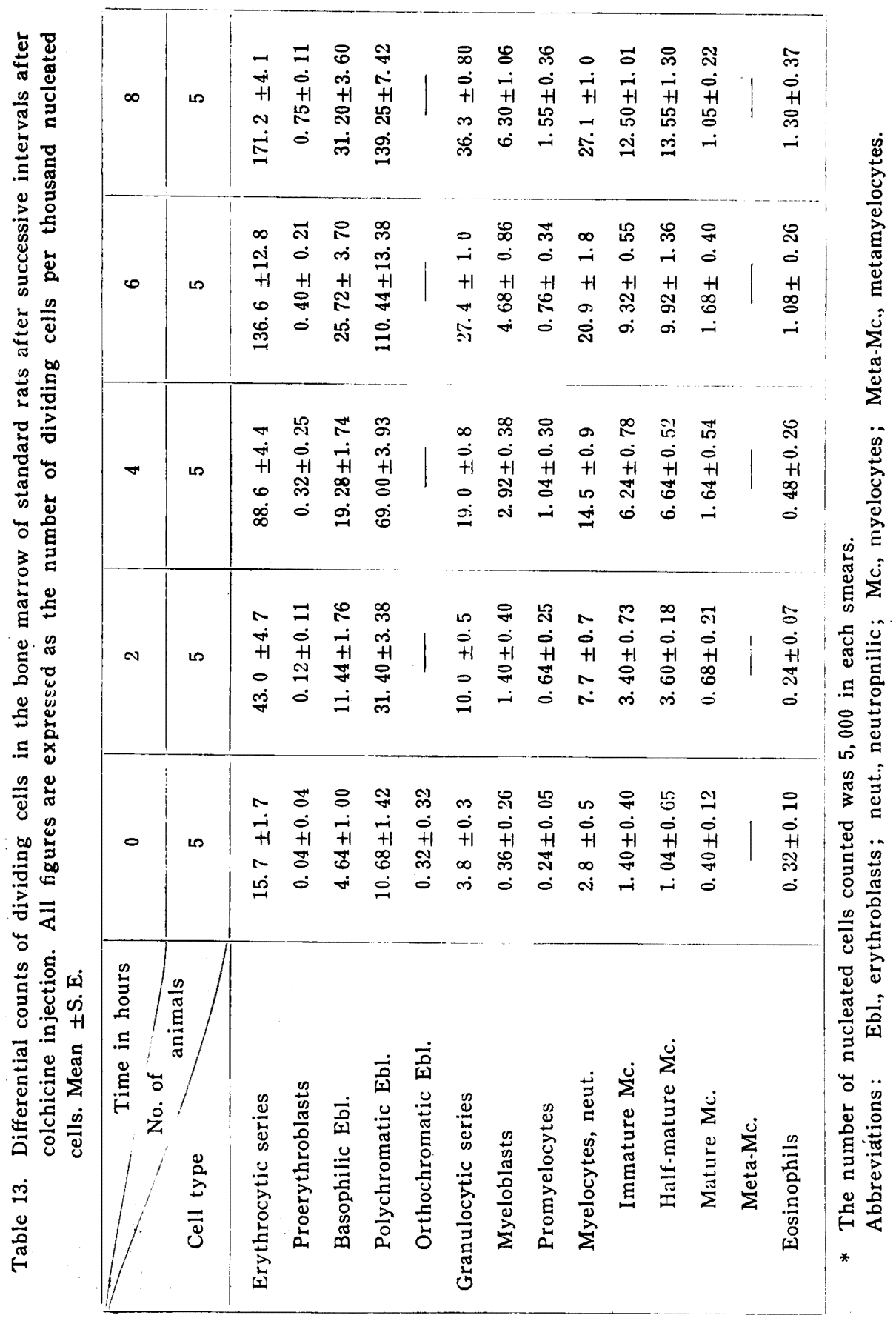

